\title{
ENTREVISTA A JORGE MEDINA MÉNDEZ
}

\author{
LAURA HUAMÁN
}

- Profesora de Planeamiento Estratégico

Área Académica de Administración, UPC

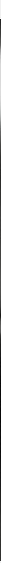

Empresario, inversionista ángel y director de empresas. Miembro de la Asociación Civil Transparencia y del Consejo Privado Anticorrupción. Miembro de consejos consultivos de varias universidades. Fue presidente de EY en el Perú, del Instituto Peruano de Auditores Independientes y de Proética (capítulo peruano de Transparency International). Ha sido miembro de los directorios de IPAE, Perú 2021 y CONFIEP, entre otras organizaciones.

Realizamos esta entrevista en un momento crítico en el país. Esta situación es una oportunidad para conversar sobre la práctica de la ética, el ejercicio profesional y las empresas.

¿Qué puede comentarnos acerca de lo que ocurre en el país en cuanto a actuar o no con ética?

Estamos viviendo un deterioro muy grave en el país. El presidente acaba de renunciar por razones que tienen que ver, de una u otra manera, con sospechas de conductas no éticas. Hasta hace poco tuvimos un presidente condenado y preso, que recientemente fue indultado. Además, hay un presidente con prisión preventiva, otro fugado con orden de captura, dos más investigados. Como si esto fuera poco, hay 67 gobernadores y exgobernadores regionales investigados y procesados por razones relacionadas con corrupción. Asimismo, de los 1,800 alcaldes que tiene el país, de una u otra manera el 90\% de ellos están involucrados con causas relacionadas a actos de corrupción. Todo esto revela algo muy grave: la manera en cómo el mal poder político se ha confabulado con el mal poder económico, para, so pretexto de ayudar a resolver los problemas de infraestructura que tiene el país, haberse organizado en redes y complicidades para lucrar indebidamente con los recursos públicos.

Esta grave situación muestra cómo ha mutado la corrupción en los últimos 15 años. En la década de los noventa, ésta fue vertical y centralizada desde la cabeza del Estado cuando el fujimontesinismo compró todo: medios, jueces, contraloría, fiscalía, políticos, etc. Luego, a partir del 2002, cuando se da el proceso de regionalización, la corrupción devino en horizontal y descentralizada. En un ambiente de débil institucionalidad varias autoridades regionales -algunas llegaron al gobierno regional con campañas financiadas con dinero ilícitoaprovecharon su poder político y económico para cometer actos de corrupción. En resumen, lo que hemos visto en estos últimos años son dos fenómenos: por un lado, la penetración de dinero ilícito en la política, básicamente en campañas electorales; y por el otro, la penetración de la corrupción en grandes obras de infraestructura. Ese es el momento que estamos viviendo. Ahora, uno diría ¿quién puede ayudarnos a cambiar esta cultura de transgresión? Y es allí donde la clase dirigente decente del país sector privado empresarial, medios de comunicación, academia, universidad y sociedad civil-, debe participar e involucrarse en ser parte de la solución, porque no le podemos pedir todo al Estado. 
Hace unos años, cuando uno hablaba de estas cosas generalmente nos decían "no pongamos el acento en la corrupción, sino en la informalidad, porque la corrupción es básicamente un problema del Estado y de los informales". Aunque parezca mentira, eso es lo que usualmente se decía. Hoy, la evidencia demuestra lo absolutamente equivocados que estaban quienes pensaban así. Fallaron en la autopercepción, pues hemos visto cómo empresas privadas hoy en día llenan las primeras páginas de los medios, no sólo por Lava Jato sino por el llamado "Club de los Constructores", entre otros casos. Es decir, la situación es muy grave y ciertamente amenaza la democracia de forma importante.

\section{¿Qué otros campos implican corrupción en comportamientos no éticos? ¿Qué otras cosas podrían considerarse respecto a conductas no éticas?}

Para ponernos en la misma página, veamos primero un tema conceptual: el campo de la ética tiene que ver con la conducta y el comportamiento, en tanto obrar bien u obrar mal. Un segundo aspecto a tener en cuenta es un principio que tiene que ver con el poder: A mayor poder, mayor responsabilidad. Porque la capacidad de hacer el bien o de hacer el mal es mayor cuando tienes mayor poder. Tercero, definamos qué es corrupción. En términos simples, es el abuso del poder, en beneficio propio y en desmedro de terceros, violando la ley y la ética, eso es corrupción. ¿Por qué es importante entender este concepto? Porque si no, uno puede pensar que corrupción es sólo coima o soborno. Pero no. La corrupción involucra más. En el campo empresarial involucra fraude contable, evasión tributaria, concertación de precios, espionaje industrial. En el campo político implica compra de votos, financiamiento ilícito, leyes con nombre propio. En el campo judicial, compra de voluntades, fallos amañados y tercerización de la corrupción. En fin, hay muchos campos en los que existen riesgos de comportamientos no éticos.

Hay un tema que creo importante comentar y tiene que ver con lo que significa en concreto qué es ejercer la ética o qué implica actuar con ética, y es éste: Se es ético cuando uno considera el impacto de sus decisiones, acciones u omisiones en los demás; es decir, obrar con ética es tener la convicción personal de que los actos de uno impactan en los demás. Es una verdad incuestionable que las decisiones de uno, siendo singulares en lugar y ocasión, son universales en significado e impacto. Cuando uno es consciente de eso y actúa en consecuencia, podría decir que está obrando con ética.

Lo que se ve hoy en el Perú es que en muchos sectores: salud, educación, seguridad, transporte, infraestructura, gobiernos municipales y regionales, y en los campos policial, judicial, político, etc., es en donde hay una tremenda falta de ética, de transparencia y de rendición de cuentas, y a todo nivel: nacional, regional, local, a nivel político, en el congreso, etc.

La corrupción está impregnada en nuestra sociedad y lo más preocupante es que se ha normalizado. El "roba, pero hace obras" se ha institucionalizado. Vivimos un ambiente de desaliento y desconfianza. Es necesario transitar de esa cultura de transgresión que hoy nos agobia hacia una cultura de integridad y transparencia. Para eso se requiere de liderazgo y coraje, se requiere cambiar el lenguaje políticamente correcto y pasar a acciones concretas, empezando con nuestro ejemplo personal. Es allí donde volvemos al otro comentario, necesitaríamos ver cómo no solamente el Estado sino también los empresarios, los académicos en las universidades, los medios de comunicación, los diplomáticos, los intelectuales, las ONGs, etc., todos tenemos un rol que jugar para salir de este letargo. Estamos como adormecidos por la corrupción, se ha naturalizado, ya es "normal", nos hemos acostumbramos y nos está haciendo mucho daño. Por ejemplo, Lava Jato le costó al Perú 1\% de menos del PBI el 2017, y crecer 1\% menos en el PBI equivale a que 150,000 peruanos no salieron de la pobreza, solo el año pasado. Es decir, la corrupción genera pobreza y miseria. La corrupción le quita oportunidades a quienes menos tienen, los enferma. La corrupción los mata. Y eso afecta la democracia, pues da lugar al caudillaje, a los "salvadores" de turno del país y sabe Dios a donde te puede llevar esa situación extrema como oportunismo político. Miremos lo que pasa en Venezuela, eso es un ejemplo.

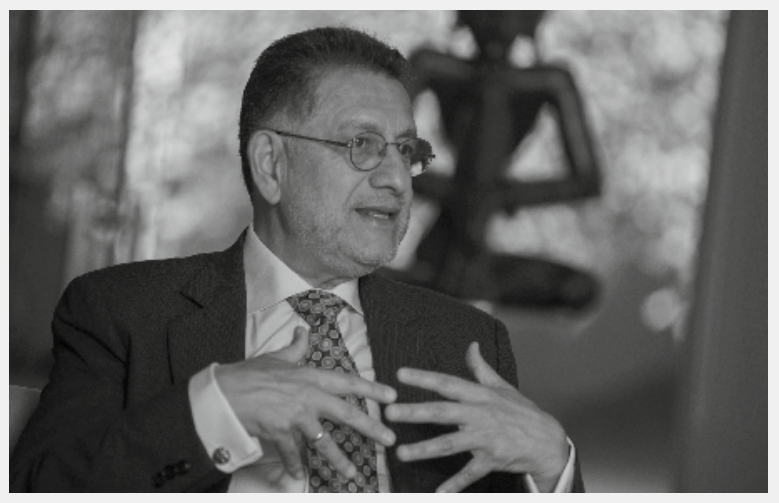

\section{¿Cómo se vinculan entonces la ética y la corrupción en cuanto al desarrollo del país?}

Se estima que el costo de la corrupción, en términos de crecimiento económico, asciende a entre 3 y $4 \%$ del PBI. Para que tengamos una idea, esos niveles superan el presupuesto nacional anual de varios sectores, como educación, salud, transportes, etc., es decir el impacto de la corrupción es brutal.

\section{Consideremos el campo de las empresas. Éstas se crean con una definición de propósito, con una visión de sus aspiraciones y plantean públicamente sus valores; prácticamente vislumbran su propio camino. ¿Dónde y en qué momento esta orientación puede perderse?}

Empecemos revisando un poquito cuál es la finalidad de la empresa. No hay empresa en el mundo que en realidad su propósito no sea resolver necesidades humanas.

Este es un concepto importante: la empresa surge para resolver necesidades. La pregunta es ¿en qué momento perdemos el paso? 
Perdemos el paso cuando dejamos de considerar para qué nos constituimos como empresa. Si lo reflexionamos con cuidado veremos que creamos empresas para resolver necesidades humanas de mucha índole: de salud, de educación, de alimentación, de vestimenta, de infraestructura, de entretenimiento, de transporte, necesidades financieras, de extracciones de minerales, etc. Todas las actividades empresariales son para resolver necesidades humanas. Cuando pierdes ese norte y le das más importancia al resultado que te va a producir esto, es decir, a la utilidad y a la rentabilidad como si ésta fuera la prioridad, entonces quizás allí empieza el problema, quizás allí es donde decides que es una buena estrategia cortar caminos y buscar atajos no éticos, quizás creas que es una buena estrategia concertar con lo no ético y ser presa fácil del extorsionador que puede venir del lado del Estado o engañar al consumidor o engañar a tus trabajadores. ¿Y todo esto por qué? Porque te confundes y crees que tu primer y principal objetivo -y quizás únicoes hacer dinero y no resolver necesidades humanas.

Otra razón, por la que perdemos el paso es porque no reconocemos que nuestra actividad genera externalidades. Me explico: si hago actividad extractiva, podría afectar el medio ambiente. Nuevamente, si mi objetivo es resolver problemas de la humanidad, no los puedo resolver a costa de crearle otro. Ser un buen ciudadano corporativo responsable implica proteger el medioambiente, tratar bien a tu personal, pagar tus impuestos. Ese es el problema, que perdemos el norte por el cual nos constituimos como empresa.

\section{¿Cómo podrían las empresas evitar perder ese norte o propósito, que usted señala, a causa de incurrir en actividades reñidas con la ética?}

La respuesta obvia es "tener un buen sistema de gobernanza corporativa". Pero ¿cómo podría uno hablar de ética empresarial, de buena gobernanza corporativa, de buen sistema de control contable interno si no cuenta con un buen programa de prevención y cumplimiento anticorrupción? Imposible. Estaría incompleto. Un programa de prevención y cumplimiento anticorrupción es fundamental hoy por hoy en nuestro país, que tiene una institucionalidad muy precaria. Las empresas no pueden pretender no correr riesgos si no tienen un programa de prevención y si no combaten expresamente a la corrupción.

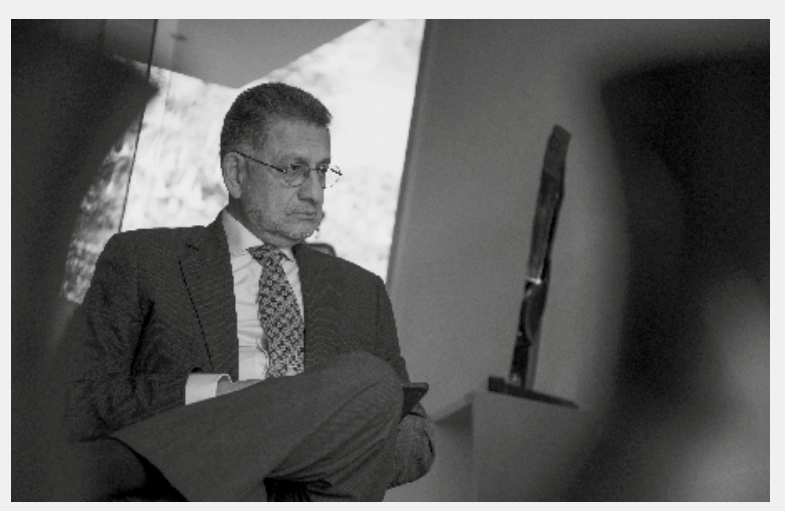

¿Implica entonces que la estrategia de la empresa debería considerar estos mecanismos de control y prevención que usted menciona?

Por supuesto que debería, ¿y por qué razón? Porque la empresa no es una isla, la empresa opera en un entorno. No es lo mismo operar en una industria, sector o lugar donde hay riesgos de contrabando o crimen organizado, que operar en un sector en el que hay muchísimas regulaciones; por ejemplo en el sector financiero, en el que la Constitución protege el ahorro, un sector que tiene una superintendencia, donde hay mucha regulación y hay que cumplir con todo eso, o sea son menos probables los casos de corrupción en un sector como el financiero que está sumamente controlado que en sectores de importación, exportación, donde tienes un problema en aduanas, contrabando y en donde hay una serie de otros riesgos. Entonces, uno no puede pretender operar ignorando su entorno y sin hacer una buena evaluación de riesgos de corrupción. Según lo que resulte de su análisis específico de riesgos, la empresa tendrá que considerar su programa de prevención y de cumplimiento anticorrupción como parte de su estrategia.

Si el Estado y las entidades públicas no avanzaran a la par del desarrollo institucional empresarial ¿le correspondería a la empresa tomar la iniciativa para mejorar el marco ético?

Existe la "Ley del Sistema Nacional de Control", que es de donde penden las actividades y la normatividad de la Contraloría General de la República; bueno, la Ley del Sistema Nacional de Control, tiene que ser reformada, está desfasada y por eso es que la Contraloría termina siendo un sheriff, un comisario, en lugar de ser una entidad que ayude en forma moderna a que haya transparencia y rendición de cuentas. Allí el Congreso tiene una tarea. Pero, volviendo a las empresas, ¿dónde debe estar este tema? En la agenda del Directorio.

Es el Directorio quien tiene la responsabilidad de cerciorarse si la Gerencia tiene en práctica un sistema de prevención y cumplimiento anticorrupción, el director tiene que hacer preguntas adecuadas y el Gerente debe saber contestar las preguntas. Un director eficaz no debería poner foco sólo en el market share y el Estado de Ganancias y Pérdidas. No todo puede ser mercado, los Directorios también tienen que pensar en el impacto positivo que las empresas deben generar en las comunidades en que operan. Deben preguntarse ¿qué externalidades estamos causando como empresa? ¿la empresa, conoce en profundidad sus riesgos de corrupción, así como las causas y las consecuencias? ¿hemos priorizado y tomado medidas frente a tales riesgos y otros que podrían estar asociados? ¿contamos con un programa de cumplimiento anticorrupción? ¿Lo supervisamos adecuadamente? ¿en qué medida cooperamos con los organismos de control para cooperar contra la extorsión y el crimen organizado? Yo creo que el rol del Directorio es bien importante en estos temas. 


\section{¿Qué más deberían hacer las empresas y sus directivos?}

Por ejemplo, deberíamos mejorar nuestra efectividad en cumplir los compromisos asumidos de los diez principios del Pacto Global' ${ }^{1}$, que se creó en Naciones Unidas hace quince años más o menos. Una empresa se adhiere voluntariamente, lo firma y tiene la responsabilidad, de informar cada año cómo ha avanzado en sus compromisos. En el Perú somos más de dos millones y medio de empresas. Eliminemos las MYPES y PYMES, nos quedamos más o menos con las medianas para arriba, eso suma varias decenas de miles, pero sólo 120 empresas peruanas han firmado el Pacto Global de Naciones Unidas, cuyo décimo principio es el de combate a la corrupción y de esas 120 empresas, muy poquitas, contadas con los dedos de una mano, ejercen un claro liderazgo en el tema de prevención y combate a la corrupción y ¿por qué pasa esto? Hay que llamar la atención a eso.

\section{¿No será que esto es un tema que es preferible postergar o ignorar?}

En el Perú no podríamos postergarlo o ignorarlo. Operamos en una aldea global interconectada e interdependiente. Mire, en el mundo se está desarrollando una corriente en donde el capitalismo está repensando su rol y han empezado a surgir movimientos como Conscious Capitalism o Inclusive Capitalism o The Shared Value Initiative, entre tantas otras, que buscan repotenciar la capacidad que tienen las empresas de impactar positivamente en la sociedades en que operan, velar por el bien común, etc., porque todo esto tiene sentido económico y empresarial y porque ese nuevo capitalismo sabe que es un su mejor interés asumir esa postura responsable, que ciertamente incluye mejorar la integridad y la transparencia. Varios líderes empresariales globales están repensando la manera en que hacen negocios, están yendo a su propósito, cuestionando la manera tradicional de hacer las cosas. Algo así deberíamos hacer en Perú. Revisitar nuestra Visión y Misión. Considerar nuestro propósito elevado, para qué nos

\begin{abstract}
1. El Pacto Mundial de Naciones Unidas (Un Global Compact) es una iniciativa internacional que promueve implementar 10 Principios universalmente aceptados para promover el desarrollo sostenible en las áreas de Derechos Humanos y Empresa, Normas Laborales, Medio Ambiente y Lucha contra la Corrupción en las actividades y la estrategia de negocio de las empresas. Con más 12.500 entidades adheridas en más de 160 países, es la mayor iniciativa voluntaria de responsabilidad social empresarial en el mundo.
\end{abstract}

Respaldado por los CEOs de las empresas que lo componen, el Pacto Mundial es un marco práctico para desarrollar, implantar y divulgar políticas y prácticas de sostenibilidad empresarial, ofreciendo a sus signatories una amplia gama de recursos y herramientas de gestión para ayudarles a implementar modelos de negocio y desarrollo sostenible. Esta iniciativa de responsabilidad social empresarial persigue dos objetivos complementarios: 1. Incorporar los 10 Principios en las actividades empresariales de todo el mundo y 2. Canalizar acciones en apoyo de los objetivos más amplios de las Naciones Unidas, incluidos los Objetivos de Desarrollo Sostenible (ODS). (http://www. pactomundial.org/global-compact/)

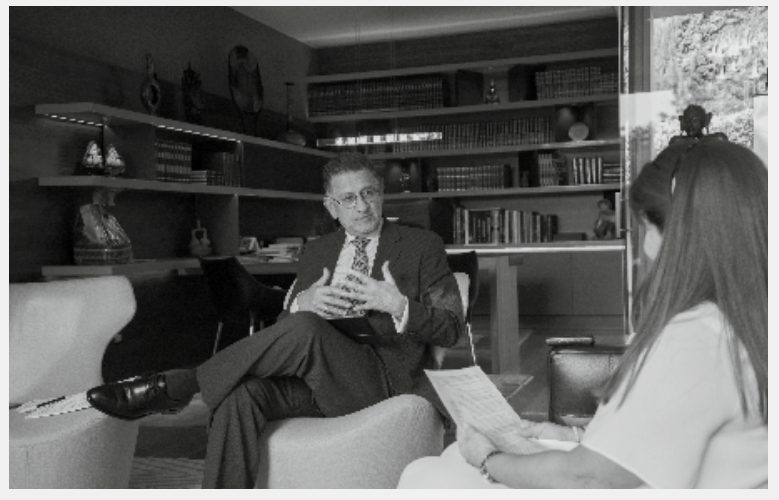

creamos. Simon Sinek, un gran pensador y conferencista, en el video de su TED Talk "How great leaders inspire action" ("Cómo los grandes líderes inspiran acción") que tiene casi 40 millones de visitas, señala que las empresas deben poner mucha atención, no tanto al ¿"qué" hacen o "cómo" lo hacen, sino al "por qué" lo hacen? Él dice que los consumidores dan su preferencia a los bienes y servicios de las empresas, no tanto por lo que son sus productos o servicios en sí o por cómo los producen, sino por las razones que tienen las empresas para hacer lo que hacen; es decir, valoran el propósito de éstas. En su discurso, Sinek muestra que cuando la empresa pone en el centro mismo de su operación a las personas, a los seres humanos, y se hace las preguntas adecuadas, mucho de su comportamiento cambia. Entonces, ya no ve a sus consumidores como un simple dato estadístico, los ve con rostro humano, prácticamente con nombres y apellidos, los ven como a sí mismos. Y entonces comienzan a cuestionar el qué hago y el cómo lo hago para dar paso al por qué lo hago. Porque el "por qué" es lo que responde al propósito elevado que debe tener toda actividad empresarial. Cuando los directorios reflexionan sobre el propósito se dan cuenta de qué cambios deberían hacer en sus conductas. Por ejemplo, dejan algunos negocios, dejan cierta rentabilidad en el corto plazo, pero se convierten en mejores ciudadanos corporativos que, en el mediano y largo plazo, los convierten en los proveedores preferidos. ¿Por qué? Porque como dice Simon Sinek, el consumidor compra el "por qué" hacen lo que hacen, se dan cuenta de ello. Acá hay algún tema para pensarlo bien en el sector empresarial peruano.

Un comportamiento ético o no corrupto, dentro de todos los esquemas que ha planteado ies entonces rentable para una empresa? ¿Genera éste un equilibrio entre prestar servicios, satisfacer necesidades, cumplir con parámetros globales, lograr ser una mejor organización y, por tanto, natural, sana y legítimamente rentable?

Para no dar una respuesta políticamente correcta definamos primero ¿qué es rentable? Preguntemos: ¿es siempre rentable el comportamiento ético, escrupuloso y transparente? No, no siempre, especialmente en el corto plazo. Quizás vas a perder negocios al inicio, quizás vas a sacrificar alguna rentabilidad. Quizás la pregunta debiera ser más bien: el comportamiento ético empresarial ¿es sostenible? Porque en realidad, de qué vale tener 
rentabilidad si luego quiebras por acciones deshonestas. Veamos lo que les pasó a muchas empresas globales o lo que está pasando ahora en el Perú, todas estas empresas asociadas a Odebrecht, a Lava Jato, no la están pasando bien. No digo que sean culpables, pues se requiere de un proceso, lo que digo es que fallaron en sus análisis de riesgos de corrupción.

Es en este contexto que es importante definir ¿qué es ser rentable? Sostener que es tener utilidades en unos cuantos años no es buena definición de rentabilidad. Rentable es ser sostenible y tú no puedes ser sostenible si estas corriendo riesgos que luego no vas a poder manejar, entonces yo preguntaría: la ética empresarial ¿es sostenible o te hace sostenible y hace que la empresa trascienda? Sin ninguna duda.

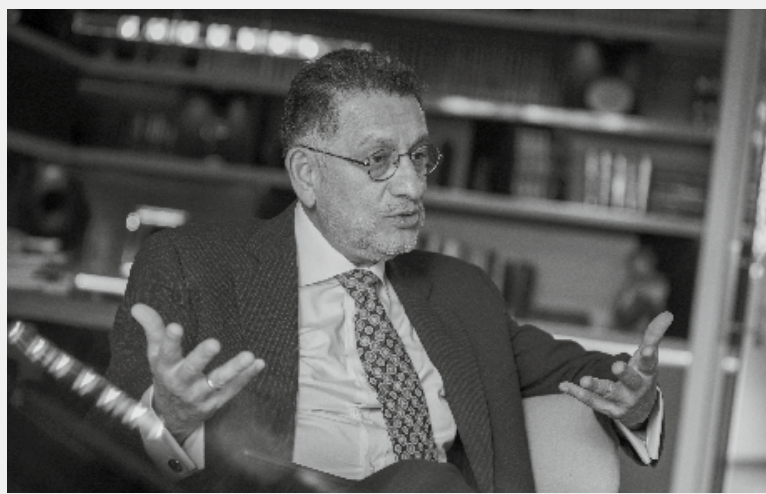

¿Dónde debería ubicarse el área organizacional encargada de compliance? Y ¿qué tanto funcionan los canales de denuncia de prácticas no éticas en las empresas? ¿O son solo formalidades corporativas?

Sería recomendable que una empresa tuviese un programa de prevención y cumplimiento anticorrupción, un buen canal de denuncias y una buena administración de éstas. Mejor aún si este mecanismo se terceriza; o sea, lo sacas de tu ámbito para que el gerente o el director no manipule el proceso. Entonces, se crea un mecanismo mediante el cual un tercero que se contrata, pero evidentemente ese tercero debe tener prestigio, respaldo y experiencia. Eso da una mayor garantía de que las denuncias van a ser gestionadas adecuadamente. Eso es la primera parte. La segunda parte, es que tienes que tener una clarísima protección al denunciante porque si no el sistema no funciona, no represalias, preservar el anonimato, etc., eso ayudaría a las empresas muchísimo.

\section{Debe ser costoso de implementar...}

No...no, eso es un tabú. Todos estos programas de prevención y cumplimiento anticorrupción, incluido los sistemas whistleblowing (sistemas internos en las empresas que permiten hacer denuncias sobre el incumplimiento de normas internas o regulaciones y leyes) se pagan solos. Un programa de prevención y cumplimiento anticorrupción no sólo detecta coimas o sobornos, también permite ahorro de costos porque identifica fallas de diversa naturaleza que exponen a las empresas a riesgos muy importantes, por ejemplo, los reputacionales. Estos programas se pagan solos, la experiencia así lo dice.

En la actualidad existen algunas organizaciones internacionales que certifican y capacitan en antisoborno y en anticorrupción a funcionarios de empresas. Tenemos el ISO 37001 y algunas empresas locales ya están participando. Entonces ¿de qué manera se debería capacitar en las organizaciones para fomentar la ética? ¿Cómo podemos medir resultados y quién la debe impartir?

Todo eso es parte del programa de prevención y cumplimiento anticorrupción. Lo que hay que decir acá es que no hay sistema de cumplimiento talla única. Un buen programa debe ser el resultado de un buen análisis de los riesgos de corrupción. Y eso va a depender mucho de en qué industria operes, si tienes o no contratos con el Estado, si tu industria es expuesta políticamente en forma importante o no, si tienes sucursales, si operas a nivel local o internacional; en fin, depende de muchas cosas. Nada de esto es ciencia ficción. Hay consultoras locales que pueden ser cualquiera de estas certificadoras o firmas de auditoría importantes que tienen experiencia internacional y también hay boutiques a nivel global que ayudan a las empresas en estos programas. El asunto es tomar la decisión de implementar estos programas.

\section{¿De qué manera afecta la tecnología y la digitalización a un comportamiento ético en las organizaciones y en su transparencia? Por ejemplo ¿podemos confiar en una firma digital? ¿La exposición de lo que hacemos de manera transparente en los portales es un reto al comportamiento ético? ¿Cómo se puede aprovechar el uso de la tecnología?}

La tecnología sin ninguna duda ayuda muchísimo y no solamente al actuar ético sino en general a cualquier actividad de la empresa. ¿Qué se puede hacer por ejemplo? Se pueden generar metodologías y mecanismos que te ayuden con alertas, señales con análisis de Big Data, mecanismos de prevención, etc. La tecnología te da señales o alertas para actuar eficaz y oportunamente. Hoy existen programas auditores que usan la inteligencia artificial para facilitar la prevención y detección. O sea, en general yo diría que la tecnología puede ayudar muchísimo a estos temas de programas de cumplimiento. Pero al mismo tiempo también pueden ayudar para que los controles sean mucho mejores y la segregación de funciones. Porque los medios cibernéticos, además, eliminan la interacción e intermediación, y a una computadora no se le puede sobornar. Entonces, la tecnología sin duda es una herramienta que puede ayudar mucho en todos estos temas de transparencia y anticorrupción. 


\section{Económicamente hablando, en los mercados competitivos no hay lugar a faltas a la ética. Si ello es así, ¿no resultaría acaso oportuno formular políticas de Estado a favor de la competitividad para reducir la corrupción?}

La competitividad busca producir más y mejor, optimizando recursos para dar más oportunidades de bienestar y desarrollo a los ciudadanos de un país. ¿Si la pregunta es si el Estado y las políticas públicas debieran incentivar la competitividad para reducir la corrupción? No tengo ninguna duda de eso. Por ejemplo, si tuviéramos una mejor educación de calidad seríamos más competitivos. Si tuviéramos menor desnutrición, tendríamos niños mucho más preparados cognitivamente para entender mejor las cosas. Si tuviéramos un poder judicial predecible, justo e independiente tendríamos mejor resolución de conflictos y disputas y eso ayuda a la competitividad, sin ninguna duda.

\section{Se es más competitivo cuando tus instituciones} funcionan. El gran problema es que por años hemos vivido engañados de separar lo económico de lo institucional. Esta idea de la última CADE de Paracas: "No más cuerdas separadas" responde a eso. Claro, ellos decían no cuerdas separadas entre lo político y lo económico. Yo digo no más cuerdas separadas entre lo institucional y el desarrollo económico, social y humano, pues ¿cómo puede un país progresar o ser sostenible si sus instituciones no funcionan?, si su poder judicial no funciona, si su policía no funciona, si la política no funciona, si el Congreso es un desastre, si la Contraloría y el Sistema Nacional de Control es malo y anticuado.

Pueden subir los precios de los minerales y mejorar nuestra economía, podemos generar más divisas, podemos tener un sistema financiero sólido, podemos sacar a más personas de la pobreza hacia la clase media, etc., pero el día que falle lo económico, si no tienes desarrollada la parte institucional, si la democracia no es fuerte, todo se te va al agua. Es lo que nos está pasando hoy. Entonces, cuando se hable de competitividad yo quiero entender que también se está hablando de reforzar la institucionalidad, de hacer las reformas judicial, electoral, laboral, etc., no solamente de reducir trámites y burocracia, sino fundamentalmente de mejorar nuestras instituciones.

¿Qué papel le toca a la Academia, es decir, cuál es su compromiso o responsabilidad en todo esto? Digamos, no en cuanto a lo que ocurrió o dejó de ocurrir, sino a lo que corresponde hacer ahora. ¿Falló la universidad?

El rol de la universidad es muy importante. De hecho, creo que nunca ha sido tan importante como hoy. Creo que la universidad, en general, tiene un enorme potencial que no está usando en estos aspectos. Explico por qué: Cuando uno dice ¿cuál es la razón de ser como universidad? Cuando leemos la Misión y la Visión de las universidades serias que hay en el país, uno encuentra muchos puntos

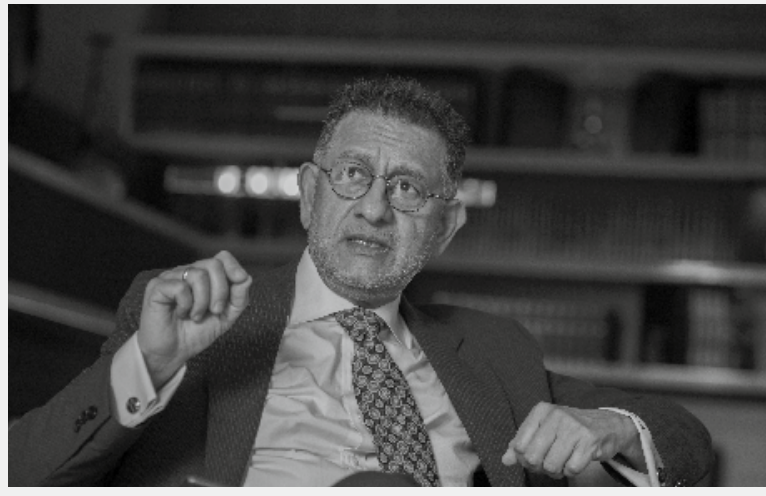

en común, encuentra propósito, valores. Me preguntaría entonces ¿están cumpliendo las universidades el rol que deberían jugar en hacer propuestas de políticas públicas para contribuir en forma efectiva con el progreso social y humano, no sólo económico del país? Yo creo que no. Creo que las universidades están hoy en una posición relativamente cómodas. Nadie les pide cuentas. Al Sector Privado, a los empresarios, sí. Nos dicen "ustedes debieran ser más activos en sugerir políticas públicas para reforzar la transparencia y la rendición de cuentas". Yo mismo soy muy autocritico respecto al rol que debe jugar el Sector Privado. Y a las ONGs también les reclaman mejorar. Pero a las universidades no; y éstas, por naturaleza propia, por su razón de ser, deberían ser más activas en estos temas. Debieran hacer propuestas de políticas públicas, deberían ejercer una mayor presión saludable, causar tensión en los hacedores de políticas públicas, manifestarse con contundencia, hacer propuestas, mojarse un poquito más. Las universidades están muy cómodas. Me pregunto ¿qué espacio privado más efectivo que el de la Academia para proponer soluciones que hagan frente a los grandes desafíos del país? Y me contesto: me cuesta trabajo pensar que haya uno más propicio que la universidad. Porque por naturaleza la universidad pertenece a un espacio donde deberían confluir todos los valores, todas las virtudes, todas las cosas buenas, la integridad, la honestidad, la transparencia, el trabajo en equipo, el coraje, la estrategia, la innovación, la tecnología y todas esas cosas, todas esas virtudes deberían trascender a la sociedad. Hago una pregunta, ¿la universidad dice algo sobre la penetración del dinero ilícito en la política? ¿dice algo sobre por qué tenemos 68 entre gobernadores y ex gobernadores presos o perseguidos o con casos de corrupción? ¿dice algo sobre cómo el narcotráfico y el crimen organizado han penetrado en el Poder Judicial, en la Fiscalía, en la Policía Nacional, en el Consejo Nacional de la Magistratura, en el Congreso? No. ¿Y por qué? El otro día yo hablaba con una autoridad universitaria y le decía te quiero hacer una pregunta ¿cuántos de tus egresados están presos por corrupción? No tienes idea, y ¿sabes por qué?, porque no está en tu agenda. ¿Cómo no va a estar la corrupción? A ver, no se dice que las universidades están para formar profesionales y para qué forman profesionales, para hacer frente a los grandes desafíos del país. 


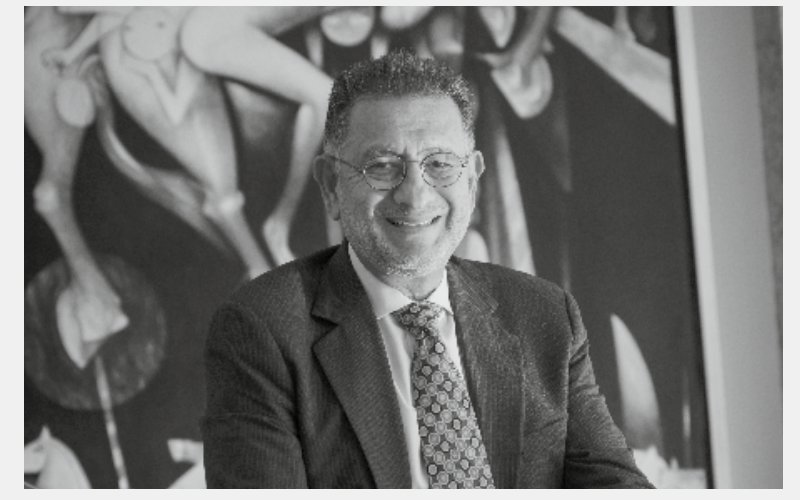

¿Y cuáles son las dos cosas más importantes que preocupan a los ciudadanos en el Perú? Corrupción e inseguridad. Yo le preguntaría a una universidad ¿Qué rol están jugando en estos temas? Claro, estoy siendo políticamente incorrecto y muy crítico, pero dicho esto, creo que la universidad tiene una gran oportunidad, diría "la gran oportunidad" de hacer realidad su propósito elevado. Si desempolvan su Visión y Misión, te puedo asegurar que encontrarán muy clarito que están dejando de hacer algunas cosas. ¿Y por qué? No lo sé. Quizás están más preocupadas en certificarse, en tener la mayor cantidad de alumnos y que éstos sean los mejores pagados en el mercado cuando se gradúen, etc., en fin, todo eso que se conoce como marketing ¿no es cierto? Pero, nos hemos preguntado ¿qué es lo que están midiendo o mejor dicho que es lo que no están midiendo los rankings universitarios de las revistas especializadas? ¿Acaso están midiendo el impacto real de la universidad en el desarrollo sostenible, no sólo en lo económico, sino fundamentalmente en lo social y humano? ¿En qué medida podemos, en efecto, hacer o proponer políticas públicas que ayuden a mejorar los derechos humanos, la democracia, la transparencia, la rendición de cuentas? Yo creo, que la universidad tiene una gran oportunidad de aporte. Y te digo algo, la universidad que empiece a hacerlo en forma contundente vas a ver cómo le va a sacar ventaja a las otras. Aquella universidad que desarrolle un nivel de conciencia y se dé cuenta del rol que le toca cumplir, de la responsabilidad que tiene en estos temas de políticas públicas, va a marcar la diferencia y va a ser la líder y las demás van a seguirla en ese propósito. Todavía están un poquito distraídas en certificar, en algunos KPIs en la competencia.

\section{¿Qué recomendaciones prácticas propone a las universidades, además de lo ya expresado, que pueda trabajarse con el estudiante a lo largo de su formación?}

Haría una pregunta: ¿tienen las universidades sus propios programas de prevención y cumplimiento anticorrupción?, ¿tienen eso en sus estrategias?, ¿sus consejos directivos lo tienen en su agenda? El primer paso, entonces, es que lo apliquen primero ellas mismas. También que lo apliquen en todas las carreras que enseñan. Pero que no sean cursos electivos. No importa si el curso es de econometría o de medicina, como profesor, yo llegaría a mi clase un día con un invitado de una empresa, por ejemplo un directivo de Siemens, empresa alemana que tuvo un caso de corrupción, y le pediría que le cuente a mis alumnos cómo sufrieron y qué hicieron para remediar sus errores, o a un ejecutivo de Volkswagen o Toyota, que nos cuenten los problemas que tuvieron y qué es lo que hicieron luego y por qué ahora son los "best in class" (el mejor de la clase), pues ya se curaron de la enfermedad. Pondría casos porque, en realidad, los estudiantes salen de la universidad en un país en el que sus dos principales problemas son la inseguridad y la corrupción y no están preparados, ipobrecitos!

Propondría más de un curso de ética, por lo menos en cuatro o cinco momentos durante la carrera de cinco años, sería materia obligatoria, un curso cada dos semestres, en fin.

Haría una pregunta a las universidades: La corrupción ¿es causa o efecto? Porqué ahí donde te equivoques en responder esta pregunta te podrías equivocar en hallar las soluciones. Los expertos dicen que la corrupción no es la causa del problema sino el efecto de otros que la originan, y entonces, en un curso hablaría por ejemplo de cuáles son esas causas que originan la corrupción. Ya definimos antes qué es corrupción: abuso del poder -y no importa si tu poder es adquirido, delegado, heredado, tienes poder-. Preguntaría cuáles son las causas de ese abuso del poder en beneficio propio, en desmedro del otro, violando la ética o la ley, ¿cuáles son esas causas? Y vamos a encontrarnos con unas cosas que el estudiante va a entender y cuando salga de las aulas universitarias lo va a tener claro. Y cuáles son esas causas. Primero, ¿cómo se ejerce la política en el Perú?, ¿cómo se financia? Allí está la madre del cordero, hay corrupción por la manera en que se financia la política. Segundo, la opacidad brutal del Estado, la falta de transparencia, que impide que los ciudadanos hagamos una veeduría ciudadana; no tenemos información clara y oportuna. No tenemos una autoridad de acceso a la información pública realmente autónoma. Tercera razón, ya lo mencionamos, sistemas de control y monitoreo desfasados e inadecuados por el sistema nacional de control que hace que nuestra contraloría sea del siglo XVIII.

Y cuarto, quizás la más compleja: nuestra débil institucionalidad. En su libro “¿Por qué fracasan los países?" de Daron Acemoglu y James Robinson, sostienen que la razón es porque sus instituciones son débiles. Los países en donde funcionan su poder judicial, su congreso, su policía, etc.... esos países son ricos. Y la otra cosa, es que son más competitivos. Si tomamos un bisturí y vamos al índice global de competitividad del World Economic Forum, que tiene doce pilares, y comenzamos a leer el pilar número uno: Instituciones, que tiene dieciséis subíndices, veremos cómo el ranking del Perú es peor que el de varios africanos y del cercano oriente, algunos que podrían ser considerados naciones fallidas. En ética empresarial, confianza a políticos, crimen organizado, confianza en el poder judicial, resolución de disputas, etc., estamos tan o más atrasados que varios de ellos; entonces, ahí está el tema: Necesitamos mejorar las instituciones y el rol de las universidades es crítico en esto. Ustedes pueden aportar mucho. Ustedes podrían ayudar a explicar bien estas cosas. Ayudarían a la Sociedad a ver las causas y no sólo el efecto. En otras palabras, a no entretenerse en la fiebre sino en lo que origina la fiebre. Si quieres matar 
la mala hierba de raíz tienes que ir a la raíz. La universidad puede hacerlo pues tiene centros de investigación, recursos, $\mathrm{PhDs}$, etc., itiene todo!

\section{¿Cómo se construye la solidez ética profesional? ¿Qué les diría a las personas que consideran que no se puede tener éxito y ser ético en este país?}

Creo que esto es un asunto de evolución, de toma de conciencia, de reflexión personal. Yo diría que hay que trabajar tu espiritualidad; no puedes desarrollar tu conciencia si no miras hacia adentro. Eso se puede hacer, inclusive se puede enseñar en la universidad. Esto no es chamanería, ni religiosidad, ni teología; esto es pura conducta humana, o sea, ética. La respuesta está en elevar nuestro nivel de conciencia para buscar el bien común.

\section{Entonces, habría que trabajar especialmente el tema de la espiritualidad.}

Exactamente. Si soy presidente de una firma o una compañía, no les puedo pedir a mis empleados que sean éticos si yo no lo soy. Tengo que predicar con el ejemplo, viviendo los valores de nuestra empresa día a día. Hay una regla coloquial que la he usado mucho en mis charlas de ética empresarial con miembros de directorios. Les decía olvídense de las reglas, olvídense de las normas, olvídense de la ética, olvídense de todo; sólo hay dos cosas que tienen que tener presente. La primera, eso que has hecho, ¿se lo puedes contar a tu hijo y no sentir vergüenza? Y, la segunda, si mañana temprano eso que has hecho apareciera en la primera página de El Comercio ¿te haría sentir orgulloso? Olvídate del resto.

\section{En su vida profesional ¿Cómo ha manejado el conflicto, de este haber existido, entre el éxito en los negocios y la ética?}

La auditoría es una actividad sujeta a riesgos y presiones. En más de una ocasión hemos tenido que enfrentar retos y lo que ha guiado nuestra conducta han sido los principios y entonces, para ser absolutamente franco, más allá de la complejidad de las situaciones que hemos enfrentado, honestamente no ha sido muy complicado tomar las decisiones correctas.

En el fondo, los dilemas éticos son complejos, pero si tienes claro lo que es actuar éticamente, entonces tomas las decisiones correctas. Y si por eso pierdes negocios y sacrificas ingresos, eso, en el fondo, es irrelevante, porque es sólo momentáneo. Actuar con ética te hace sostenible, porque tienes la mirada en el largo plazo. Y como estamos hablando de ética empresarial, definámosla de una manera práctica: ética empresarial es la convicción personal de que no todas las decisiones de uno dan lo mismo. Ética empresarial es tener conciencia de que nuestras decisiones, acciones $\mathrm{u}$ omisiones no valen por igual, y no valen por igual porque tienen consecuencia en los demás, porque -como dije antes- siendo nuestras decisiones singulares e individuales en lugar y ocasión, son universales en significado e impacto, porque tienen consecuencias en los demás. Pero si te pones una venda y no ves, o lo que es peor no quieres ver -que es lo más amoral que puede existirentonces ahí tienes un grave problema. Nuevamente, hay que tener muy claro lo que es ética empresarial: la convicción personal de que mis decisiones no valen lo mismo porque impactan en los demás.

\section{Proética celebró su décimo quinto aniversario de vida institucional en 2017. ¿Cuáles han sido los principales logros y cuál es la agenda pendiente?}

En una época muy triste y compleja para nuestra historia republicana -en el 2000 y 2001-, después de la segunda reelección cuando se destaparon los vladivideos y salió a la luz toda esa corrupción brutal sistémica que se había tejido en base a una serie de redes y complicidades, fue cuando nació Proética como una suerte de ojos y oídos del ciudadano para denunciar, para alzar su voz, para decir no queremos esto en el Perú, queremos una sociedad próspera, justa y predecible. A partir de allí Proética ha tenido una serie de actividades. Probablemente una de las más conocidas es el estudio que hace a nivel nacional cada dos años: el de percepciones de corrupción, que es muy consultado y es como una suerte de termómetro que mide si estamos avanzando o retrocediendo.

El otro tema que ha hecho Proética, sobre todo en provincias, es que ha sido capaz de organizar y colaborar

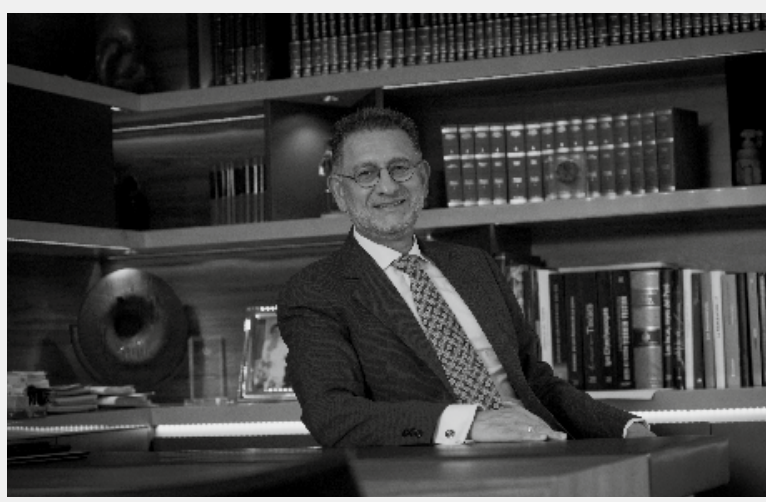

con veedurías ciudadanas para que los vecinos se hagan cargo y vean y vigilen a sus autoridades locales. Hace un par de años Proética creó una red de voluntariado, básicamente en Lima, conformado por profesionales de alto nivel con el objetivo de influir en los hacedores de políticas públicas y hacer propuestas en pos de la transparencia, la integridad y la rendición de cuentas.

Proética ha estado en cosas estratégicas como hacer propuestas de políticas públicas y en cosas tácticas como hacer movilizaciones, manifestaciones, presión ciudadana.

Dicho eso, y para hablar con toda franqueza de expresión, hay una agenda pendiente, no sólo Proética sino, en general, para varias organizaciones de la sociedad civil: tienen que ser menos sesgadas. Si tengo que hacer una autocrítica a Proética, ésta sería que debería ser más plural, inclusiva y convocante. No debería ser "anti". Lo único "anti" debe ser anticorrupción, punto, no más. Porque no puedes encarnar un movimiento cuyo objeto sea trabajar por un Perú libre de corrupción si es que tienes determinado sesgo político y solo eres afín a 
determinada posición política, porque entonces fallas. Lo que quiero decir es que debemos ser absolutamente neutros e independientes en temas políticos y ser igual de críticos con cualquier tendencia. Cada uno puede tener sus preferencias personales, pero institucionalmente hablando, hay que ser neutros políticamente.

Sobre las agendas pendientes necesitamos mejorar nosotros. O sea, no me mandes a correr la maratón si es que no tengo buena fibra muscular y no estoy preparado. Para prepararme y correr esa maratón, que es luchar contra la corrupción, necesito también recursos y ahí no hemos sido muy eficaces. Porque no hemos desarrollado el sex-appeal suficiente para generar muchas más contribuciones, ciudadanía de diferentes sectores para apoyar el movimiento anticorrupción. Probablemente por lo primero que decía. Porque nos ven sesgados, nos ven "caviares", nos ven muy sesgados a determinado sector, y eso si bien no necesariamente es justo, ciertamente algunas razones hay. Lo tercero es que tenemos que modernizarnos. Mientras el movimiento anticorrupción camina, la corrupción corre, y cada vez estamos más separados, y cada vez va a ser más difícil luchar contra ella. Entonces tenemos que modernizarnos, tenemos que usar más tecnología y comunicaciones, tenemos que usar más las redes sociales para atraer a más voluntarios, tenemos que ser una organización pro-bono, atraer al sector privado, las universidades, la academia, los medios, intelectuales, diplomáticos, para que se sumen a la causa y ser un movimiento potente.

\section{¿Un mensaje final a modo de epílogo?}

Hay que pensar en los jóvenes. Es una fuerza maravillosa a la que debemos sumar al movimiento anticorrupción. De la mano de la universidad se pueden llevar a cabo iniciativas interesantes, porque la universidad tiene a los jóvenes. Depende entonces del liderazgo que ejerzamos en este sentido. 